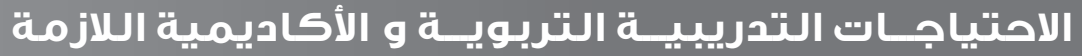

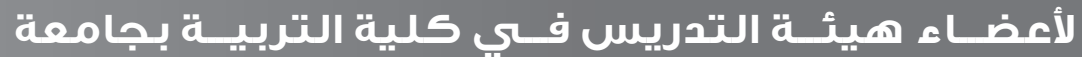

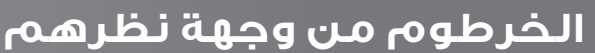

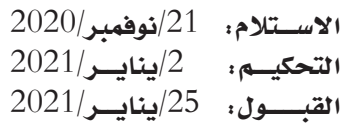

(c) 2021 University of Science and Technology, Yemen. This article can be distributed under the terms of the Creative Commons Attribution License, which permits unrestricted use, distribution, and reproduction in any medium, provided the original author and source are credited.

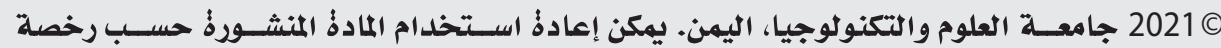
مؤسسة المشاع الإبلاعي شريطة الاستشهاد بالمؤلف والمجلة. 
الاحتياجات التدريبية التربوية و الأكاديمية اللازمة لأعضاء هيئة التدريس

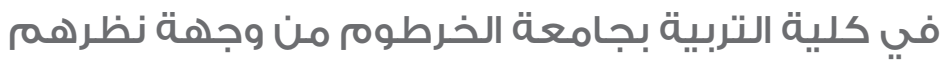

الملخص:

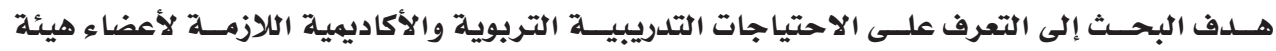

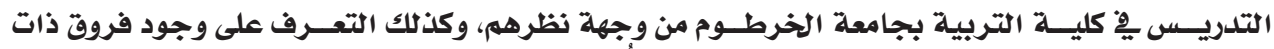

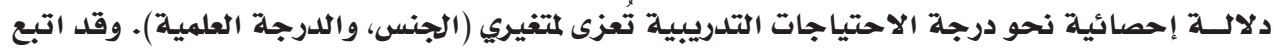

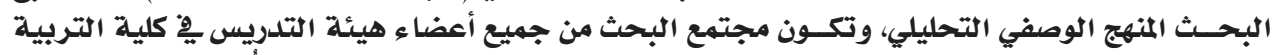

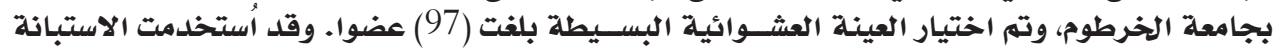

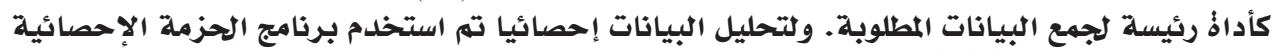

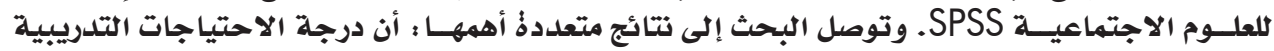

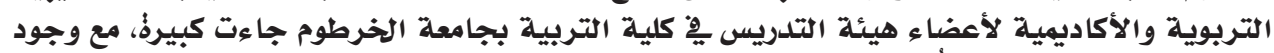

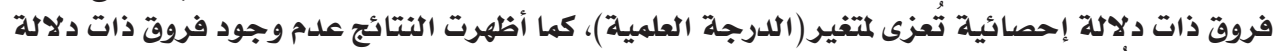

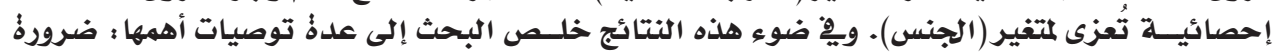

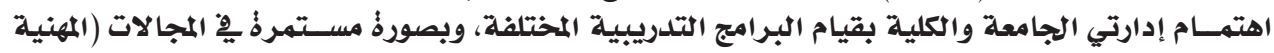

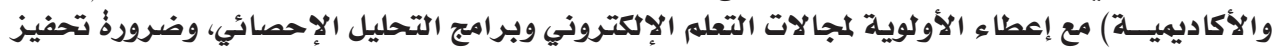

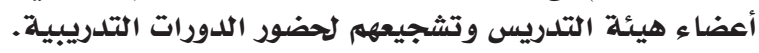

الكلمــات المفتاحية ؛ التدريـب، الاحتياجات التربويــة، الاحتيـاجات الأكاديميــة، كلية التربية

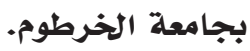




\title{
Necessary Educational and Academic Training Needs at the College of Education, University of Khartoum from the Faculty Members' Perspective
}

\begin{abstract}
:
The research aimed at identifying educational and academic training needs required for faculty members in the College of Education at the University of Khartoum from their point of view, as well as to find out any statistically significant differences in the degree of training needs due to two variables (gender and academic degree). The research followed the descriptive analytical approach, and the research population covered all faculty members of the College of Education, University of Khartoum. A simple random sample of (97) members was selected. The questionnaire was used as the main tool for collecting the required data. To analyze the data statistically, the SPSS program was used. Major findings revealed that the degree of educational and academic training needs of faculty members in the College of Education at the University of Khartoum was high, with statistically significant differences attributed to the variable (academic degree). The results also showed that there were no statistically significant differences attributed to the variable (gender). In light of these results, the research concluded with a set of recommendations, including: the university and college administrations should pay attention to various training programs on a continuous basis in both professional and academic fields, priority should be given to the areas of e-learning and statistical analysis, and faculty members should be encouraged to attend training courses.
\end{abstract}

Keywords: training, educational needs, academic needs, college of education at the university of Khartoum. 


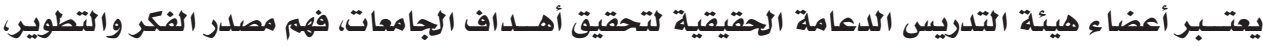

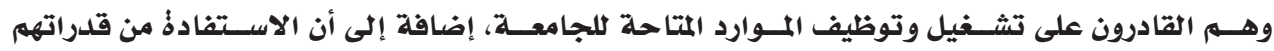

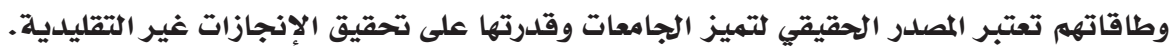

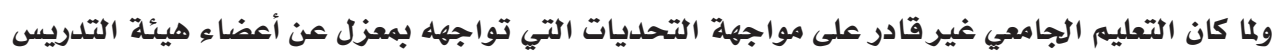

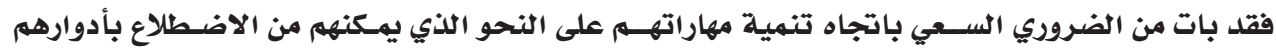

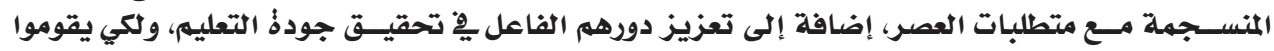

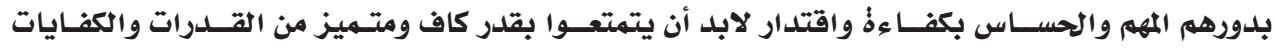

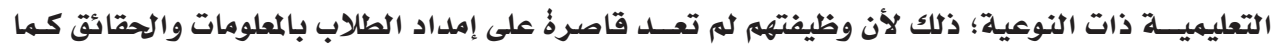

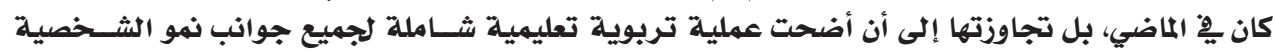

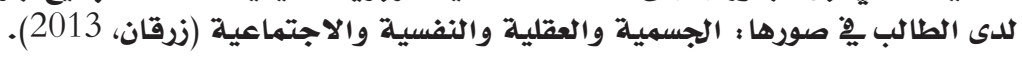

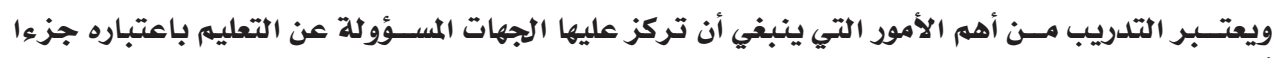

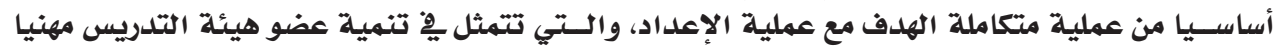

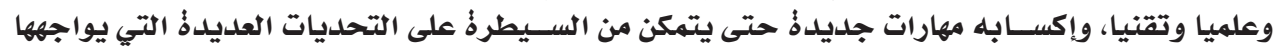
أثناء عمله (العاجز، اللوح، وابله مهارات جديات والثقر، 2010).

وتشـير مجموعة من الدراسات مثل دراسة الشـعيبي (2020) ودراسة الشريف (2019) ودراسة التهية التويجي

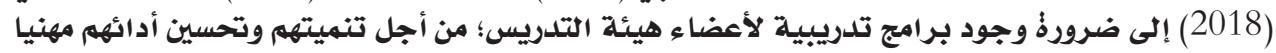

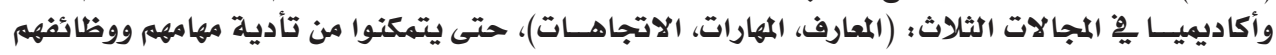

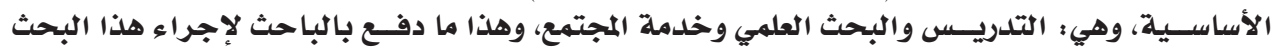

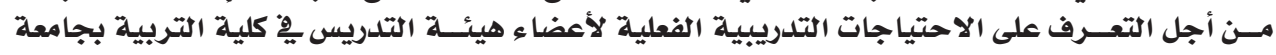
الخرطوم.

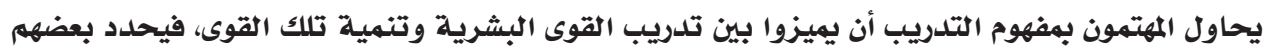

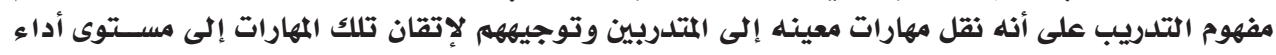

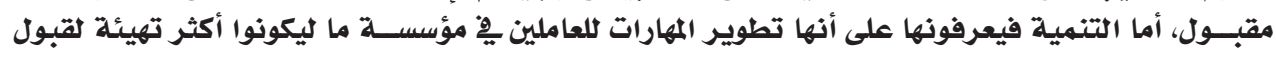

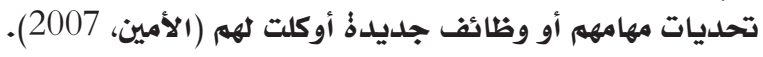

$$
\text { ويمكن ذكر بعض تعريفات التدريب فيما يلي: }
$$

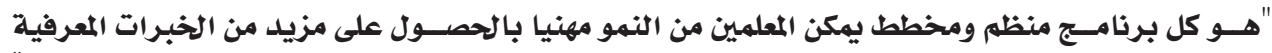

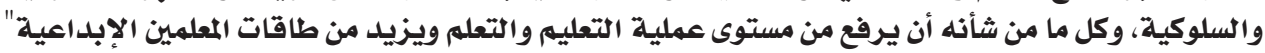
(طعيمة والبندري، واكل مانس من شأنه 2004، 28).

كذلك عُرف بأنه "الجهود الإدارية أو التنظيمية التي تهدف إلى تطوير قدرةٌ الفرد على أداء عمل معين

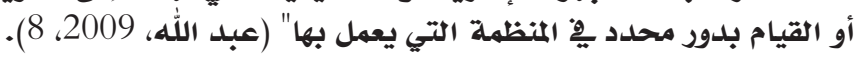
فمن خلال هذين التعريفين السابقين نستطيع إدراك أن التدريب: - نشاط إنساني.

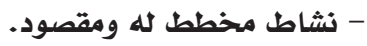
- يهدف إلى تنهية وتطوير معارف ومهارات واتجاهات المتدربين نحو مجال مجال معين. - يهدف إلى إحداث تغييرات يِّ جوانب مختارةٌ لدى المتدربين. 
ويعتبر التدريب عملية مهمة لجميع العاملين ويف مختلف المجالات، وذلك للأسباب الآتية :

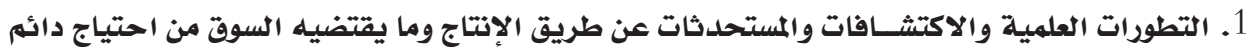

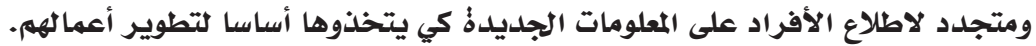

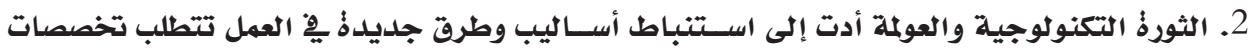

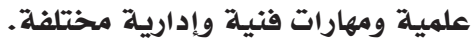

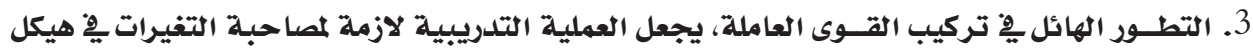
القوى العاملة.

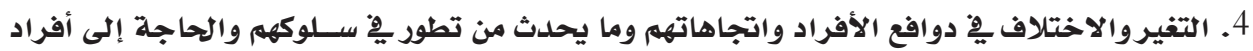
متعددي المهارات يجعل التدريب الهادف إلى تعديل التهاف السلوادك أمرا حتميا (الأمين، 2007). ويرى العاجز وآخرون (2010) أن الأسس التي تقوم عليها برامج التدريب ترتكز على الآتي: 1. وضوح وواقعية البرنامج التدريبي.

2. تلبية التدريب لحاجات تلدريبية حقيقية التونية.

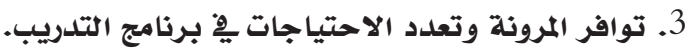

4. اتسام عملية التدريب بالاستهرارية. 5. استثهار التدريب لوسائل التقنيات المتاحة.

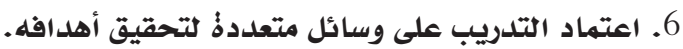

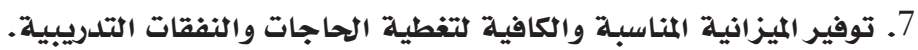
8. اختيار الوقت المناسب للمتدربين، والتدريب بأقل وقت وائل ممكن.

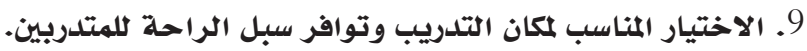

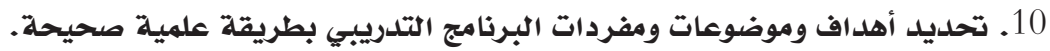

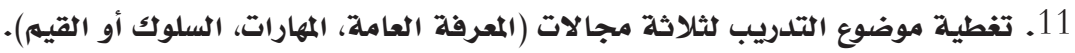

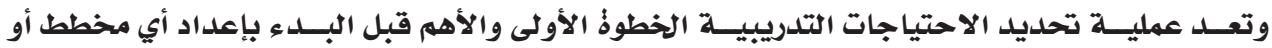

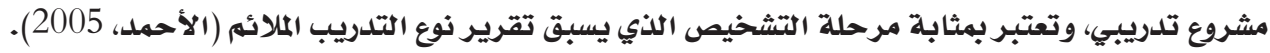

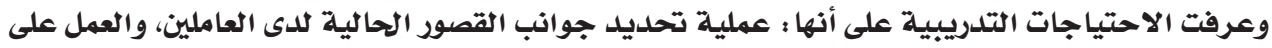

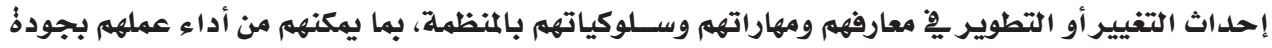
عالية (الجربوع، 2010).

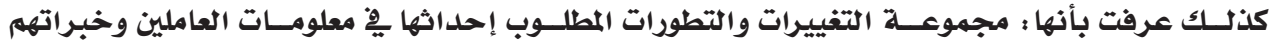

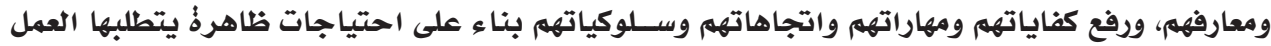
(عايث، 2010).

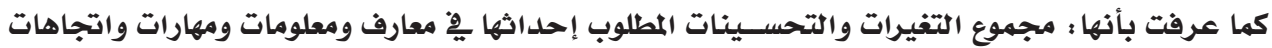
العاملين بغرض التغلب على العقبات التي تعترض سير العمل وتحول دون تحقيق أهداف المؤسسة (السالماتهات واتحات .$(2009$

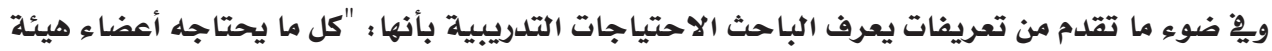

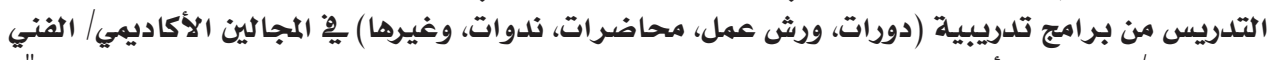

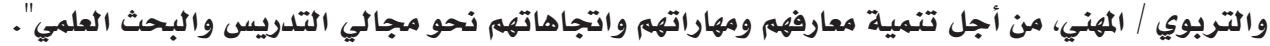


وتوجل العديد من الأسباب التي دعت إلى تحلديل الاحتياجات التدريبية، نذكر منها على سبيل المثال :

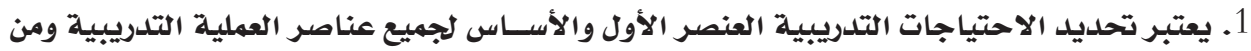

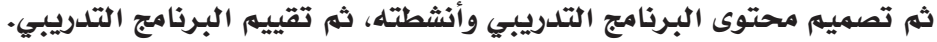

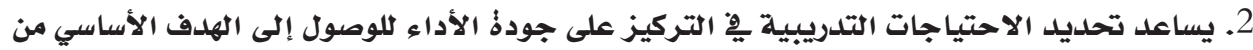
التلدريب.

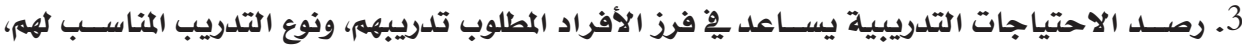
والنتائج المتوقعة منهم.

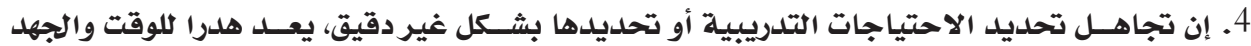
والمال (نجم وأبو دية، 2020).

وهنالك العديد من الدراسات السابقة العربية والأجنبية تناولت موضوع الاحتياجات التدريبية لأعضاء

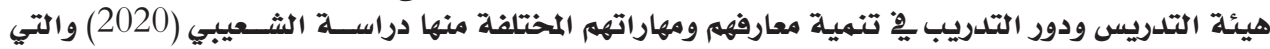

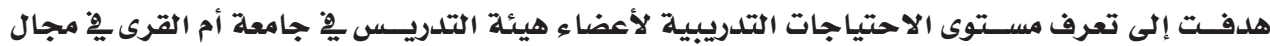

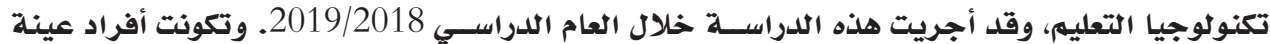

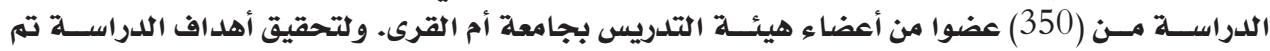

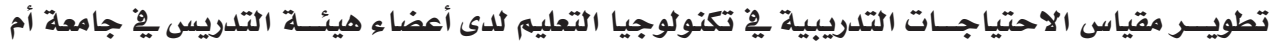

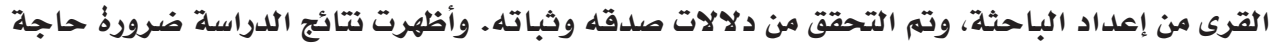

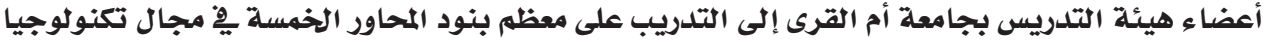

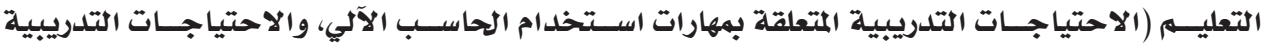

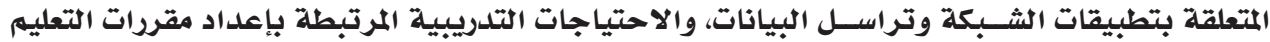

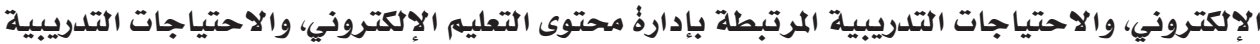

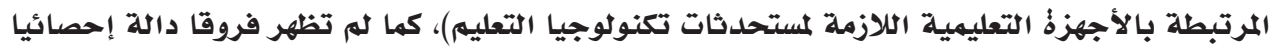

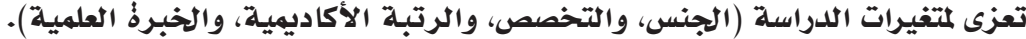

وهلدفت دراســة الشــريف (2019) إلى تعرف الاحتياجــات التدريبية لأعضاء هيئــة التدريس بالكلية

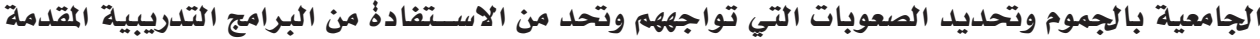

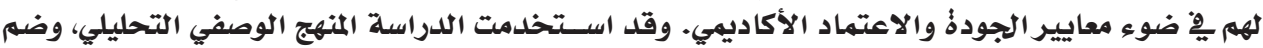

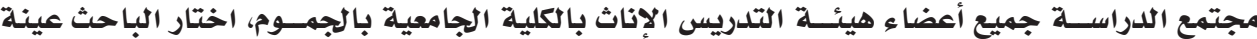

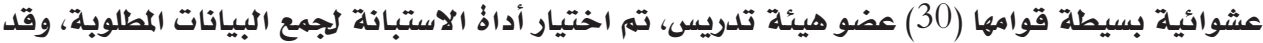

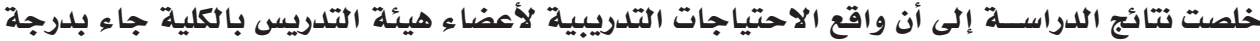

متوسطة.

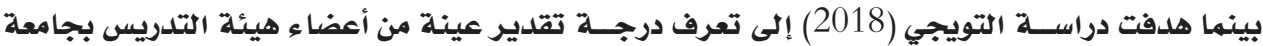

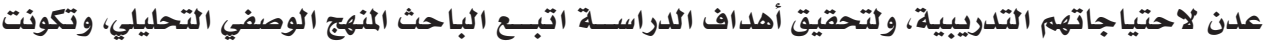

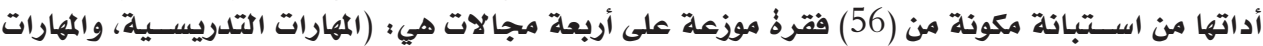

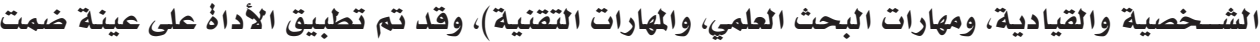

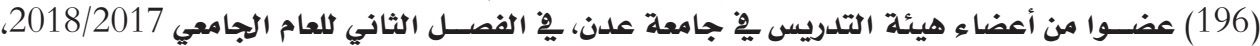

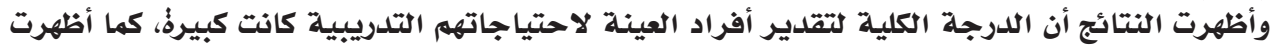

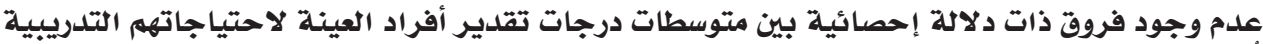
تعزى لمتفيرات (الجنس، نوع الكلية، الرتبة الأكادية ديمية).

كما هلدفت دراسة بلدارنة والصالحين وحميدات (2018) إلى تعرف الاحتياجات التدريبية لأعضاء هيئة

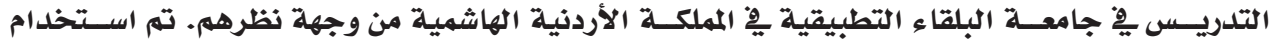

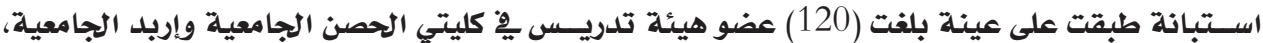




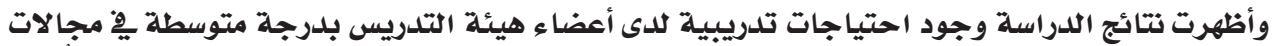

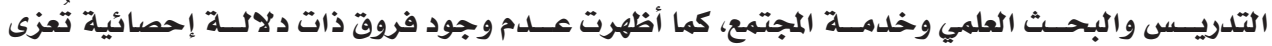

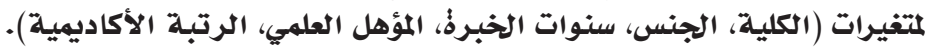

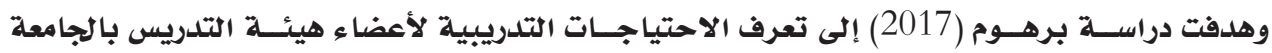

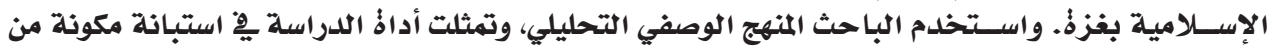

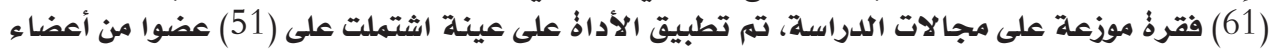

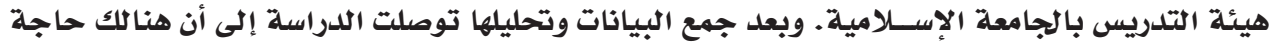

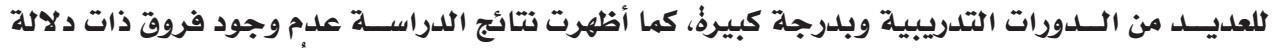

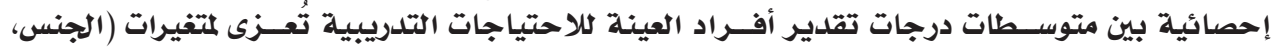

سنوات الخلدمة، الدرجة ألدونة العلمية).

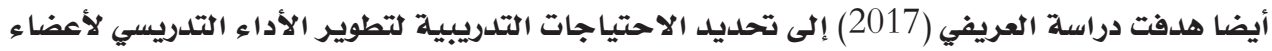

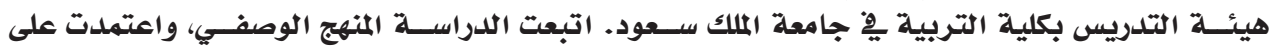

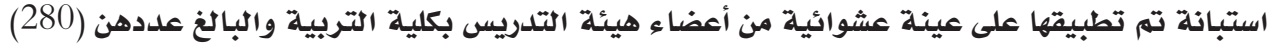

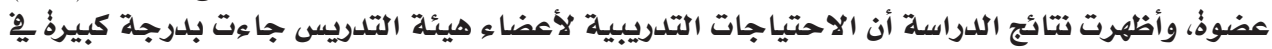

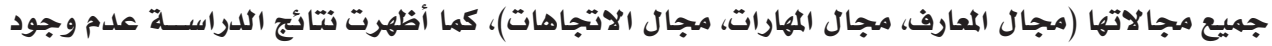

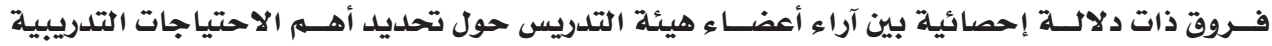

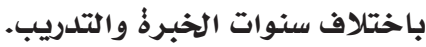

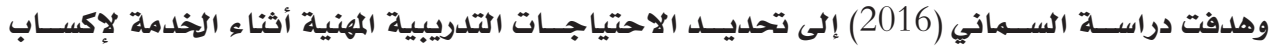

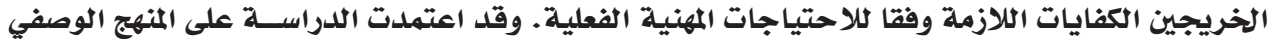

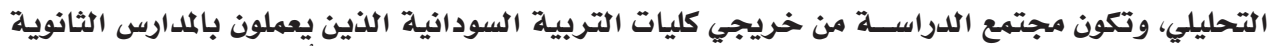

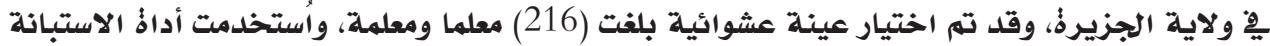

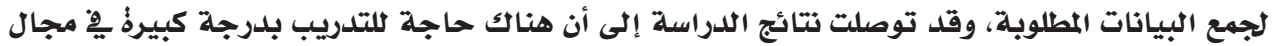
تخطيط التدريس وتنفيذه.

كما هدفت دراســة الطيب (2015) إلى تحديد الاحتياجـات التدريبية لأعضاء هيئة التدريس فِّف مجال

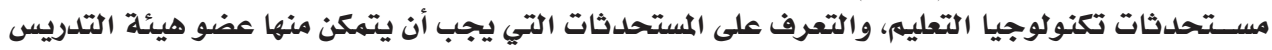

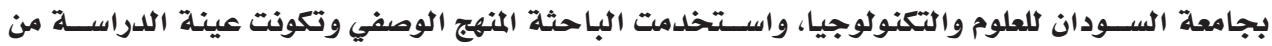

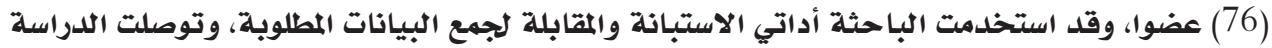

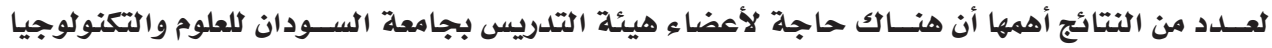

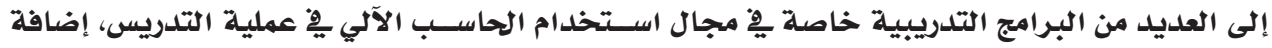

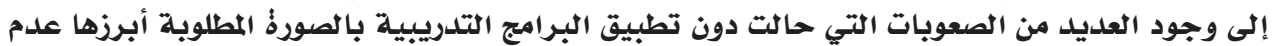

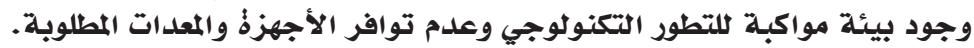

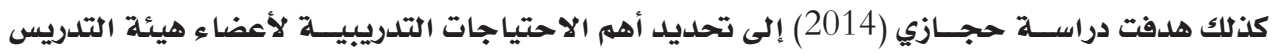

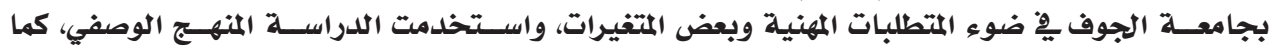

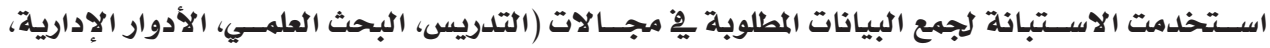

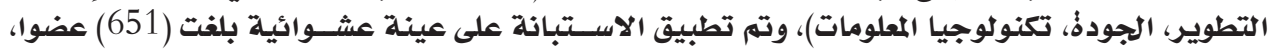

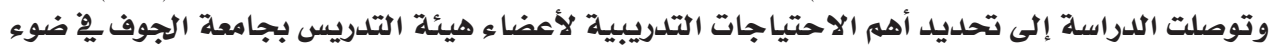
المتطلبات المهنية والتي جاءت الدرات بلدرجة كبيرة.

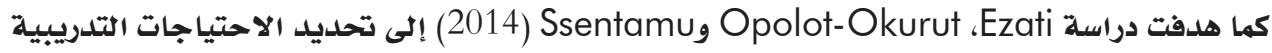

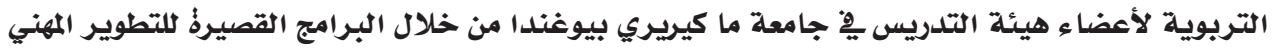




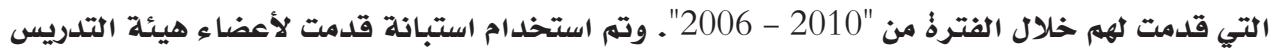

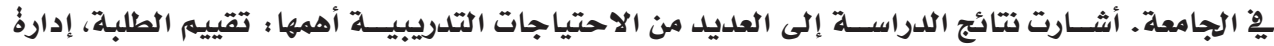

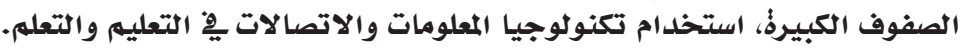

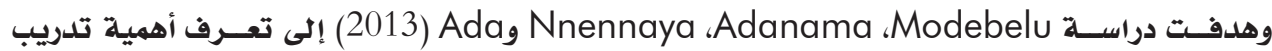

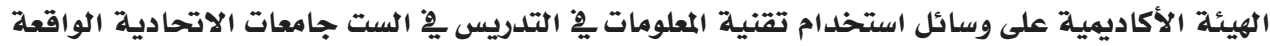

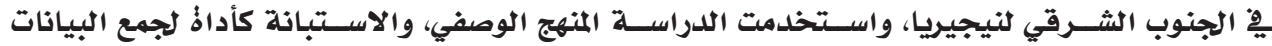

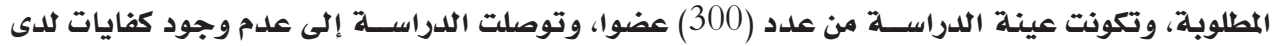

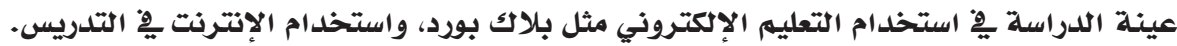

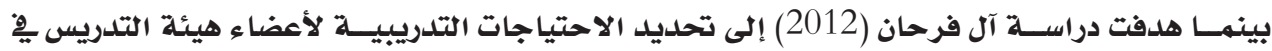

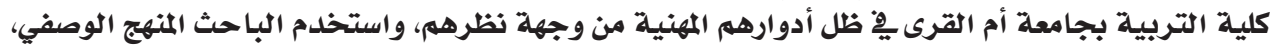

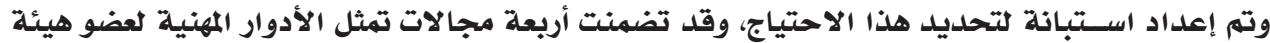

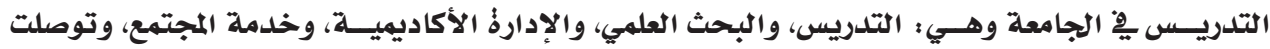

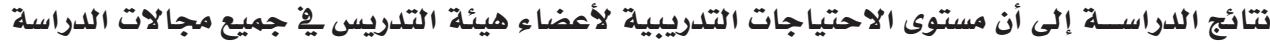

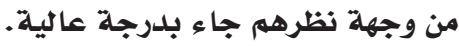

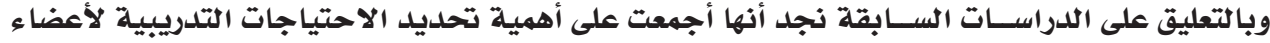

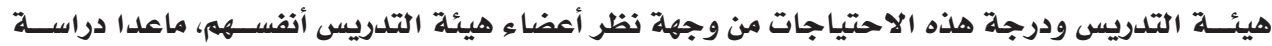

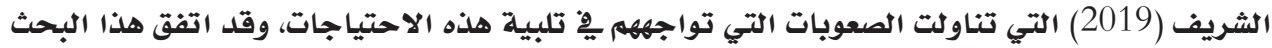

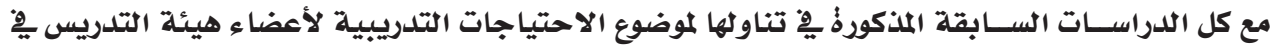

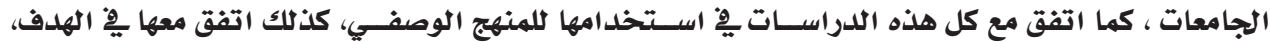

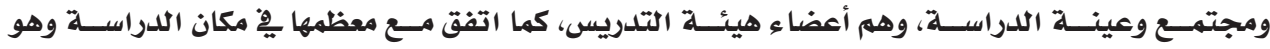

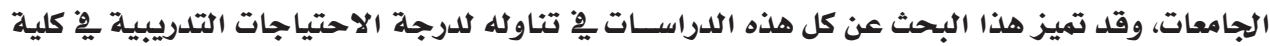

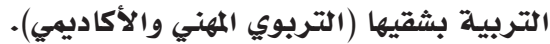

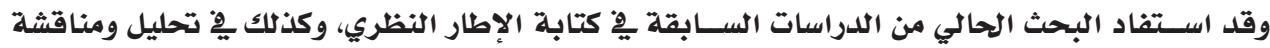
نتائج البحث، وِِّ طريقة صياغة النتائج والتوصيات والمقترحات، إضافة إلى توفير المراجع المطلوبة المبلة.

\section{مشثكلة البحث وأسئلته:}

نبعت مشكلة البحث من خلال عمل الباحث يِّ كلية التربية بجامعة الخرطوم، حيث لاحظ حاجة أعضاء

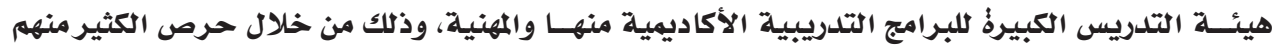

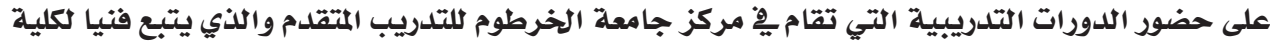

التربية وإداريا لجامعة التورات التدربية الترطي

وهنالك بعض الدراسـات السودانية التي تناولت موضوع الاحتياجات التدريبية لأعضاء هيئة التدريس،

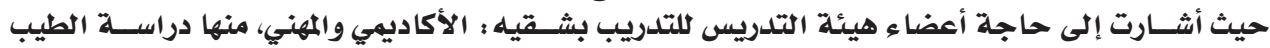

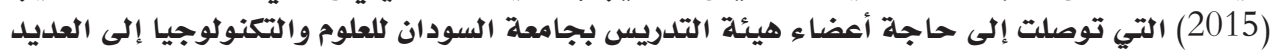

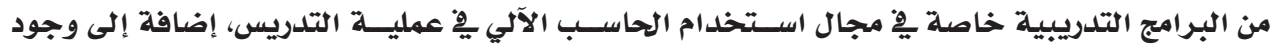

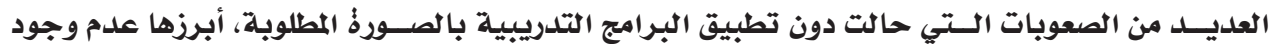

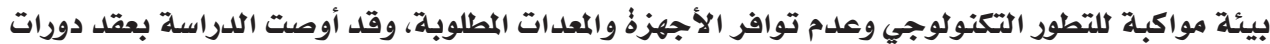

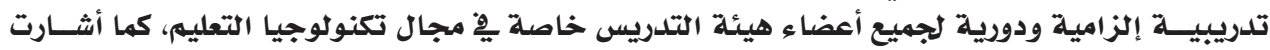

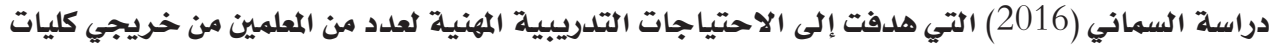

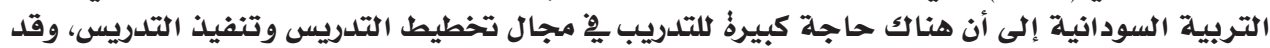

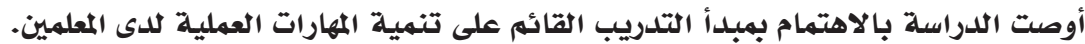


وبناءا على ما سبق يكون السؤال الرئيس للبحث هو:

مـا الاحتياجات التدريبية الازمة لأعضـاء هيئة التدريس ِِّ كلية التربية بجامعة الخرطوم من وجهة نظرهم؟

وينبثق منه السؤالان الآتيان :

1. ما درجة الاحتياجات التدريبية التربوية لأعضاء هيئة التدريس فِّ كلية التربية بجامعة الخرطوم من وجهة نظرهم؟ ما درجة الاحتيات

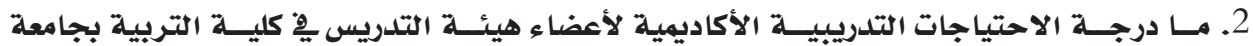

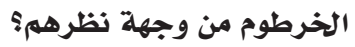

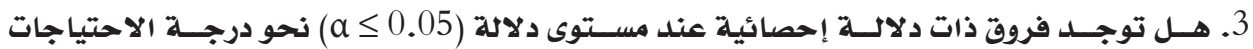

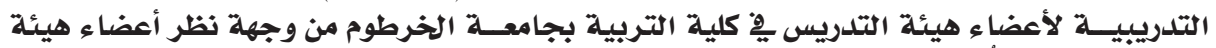

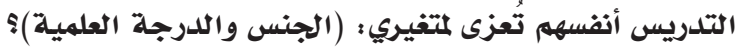

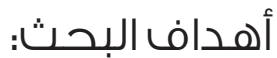

1. التعرف على درجة الاحتياجات التدريبية التربوية لأعضاء هيئة التلدريس فِ كلية التربية بجامعة

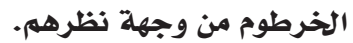

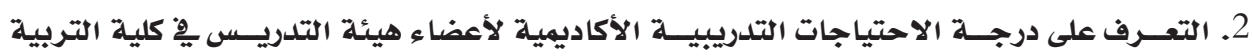

بجامعة الخرطوم من وجهة نظرهم.

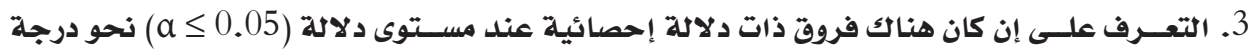

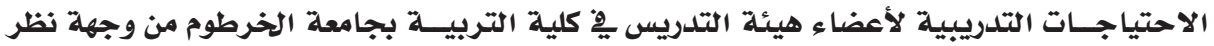

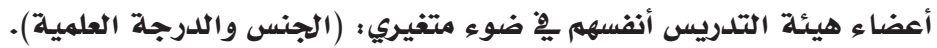

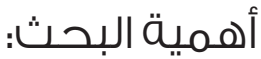

الأهميية العلمية :

1. قد يفيد الباحثين وطلاب الدراسات العليا كمرجع للدراساتهم يِّ هذا المجال.

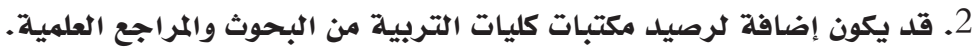

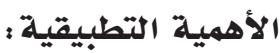

1. تعريف إدارةٌ الكلية بأهم الاحتياجات التهات التدريبية لأعضاء هيئة التدريس ومساعديهم.

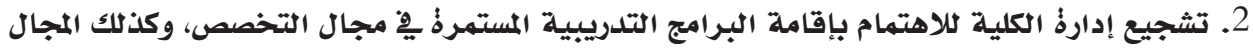

التربوي المهني لأعضاء هيئة التدريس.

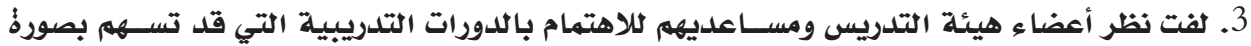

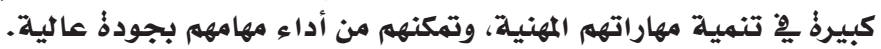

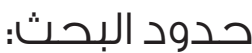

> الحلدود البشرية : وهم أعضاء هيئة التدريس ومساعديهم ِِّ كلية التربية بجامعة الخرطوم.

> الحلدود المكانية ؛ كلية التربية بجامعة الخداية الخرطوم.

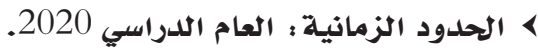

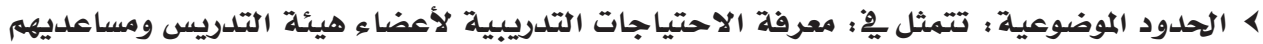

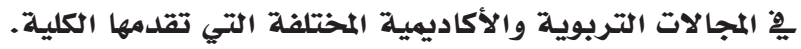




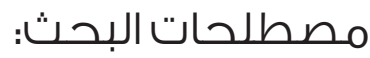

ه التدريب: هو "عملية سلوكية يقصد بها تفيير الفرد بهلف تنهمية ورفع كفايته الإنتاجية" (حسن، علي،

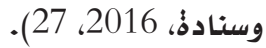

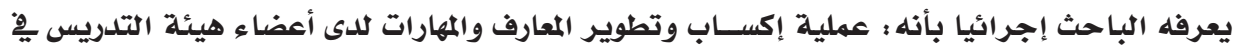
كلية التربية بجامعة الخرطوم حتى يتمكنوا من تأدية مهامهم بالصورةٌ المطلوبلة.

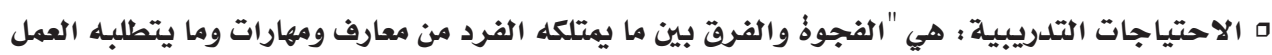
الذي يقوم به" (التويجي، 2018، 119).

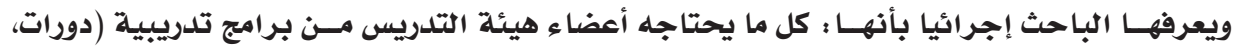

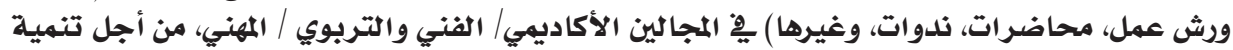

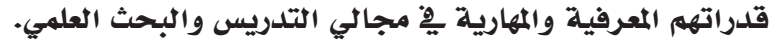

ه عضو هيئة التدريس: هو كل من يعمل فِّ مجال التدريس فِّ كلية التربية بجامعة الخرطوم من درجة

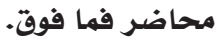

$$
\text { منهج البحثية البحث وإجـراءاته: }
$$

استخلدم الباحث المنهج الوصفي التحليلي لإجراء البحث.

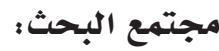

تكــون مجتمع البحث من أعضاء هيئة التدريس ومســاعديهم ِِّ كلية التربية بجامعة الخرطوم، والبالغ

عددهم (212) عضون مجنما. عينة البحث:

تم اختيار عينـة عشـوائية بسـيطة من مجتمــع البحث بلغ عددها (97) عضوا يعملــون بِ كلية التربية

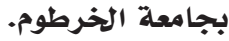
وصف العينة ؛

\begin{tabular}{|c|c|c|c|}
\hline النسبة المئوية & العدد & التصنيف & المتغير \\
\hline 38.1 & 37 & ذكر & الجنس \\
\hline 61.9 & 60 & 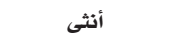 & \\
\hline 100 & 97 & المجموع & \\
\hline 7.2 & 7 & مساعد تدريس & الجنس \\
\hline 32.0 & 31 & محاضر & \\
\hline 49.5 & 48 & أستاذ مساعد & \\
\hline 11.3 & 11 & أستاذ مشارك & \\
\hline 100 & 97 & المجموع & \\
\hline 20.7 & 20 & الأقسام التربوية & الأقسام الأكاديمية \\
\hline 54.6 & 53 & الأقسام العلمية & \\
\hline 24.7 & 24 & الأقسام الأدبية & \\
\hline 100 & 97 & المجموع & \\
\hline
\end{tabular}
جدول (1): توزيع أفراد العينة حسب الجنس والدرجة العلمية والأقسام الأكاديمية 


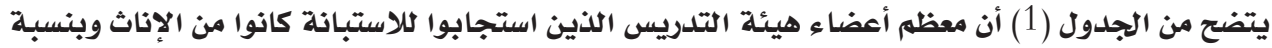

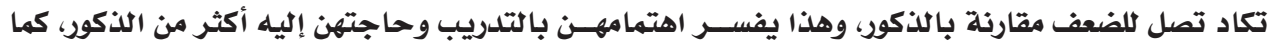

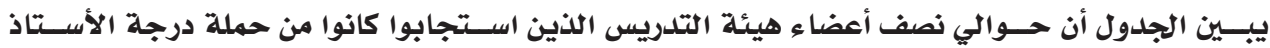

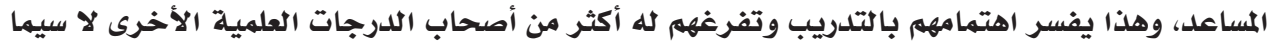

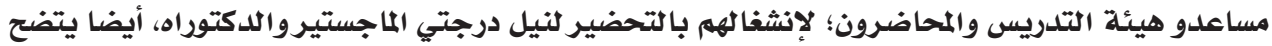

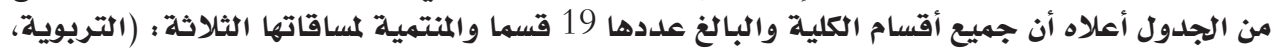

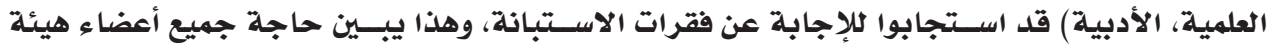

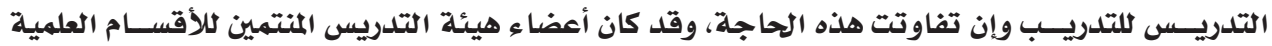

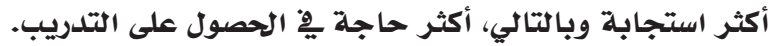

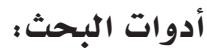

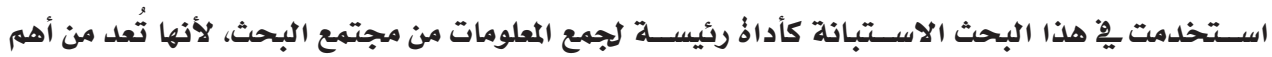

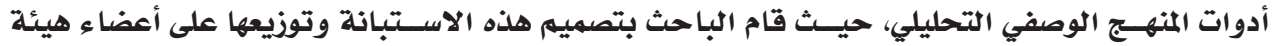

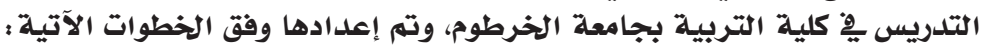

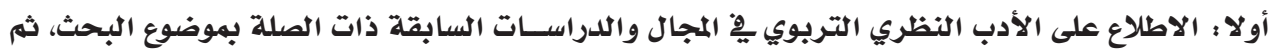

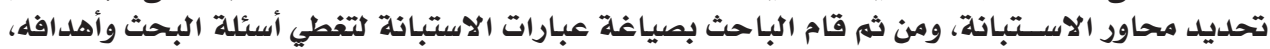

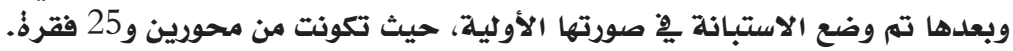

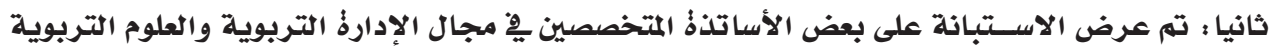

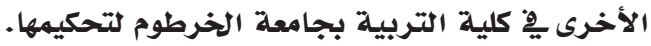
ثالثا : تم إجراء بعض التعديلات الدلازمة، ومن ثم تم صياغة عباراتها ِِِ صورتها النهائية، وقد اشــتملت الاستبانة على قسمين هما :

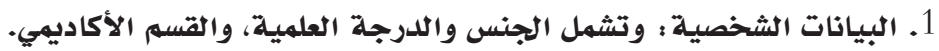

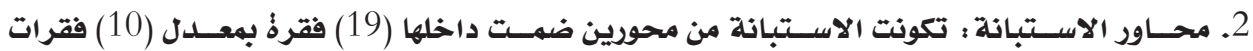

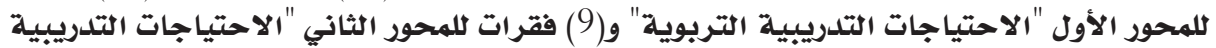

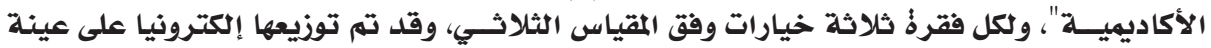

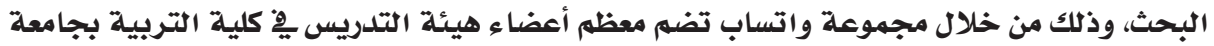
الخرطوم.

جلدول (2): تصنيف استجابات العينة وفق المقياس الثلاثي

\begin{tabular}{|c|c|c|c|}
\hline منخفضة & متوسطة & كبيرة & الاستجابة \\
\hline 1 & 2 & 3 & الدرجة \\
\hline
\end{tabular}
يقصد بالثبات قدرةٌ الأداذُ على إعطاء نفس النتائج عند تطبيقها على مجتمع مماثل. ولمعرفة الثبات تم اســتخدم معادلة معامل (a) ألفا كرونبــاخ، وقد نتج عن هذا التطبيق أن معامل الثبات يساوي (0.90). صلدق الاستبانة : مانة

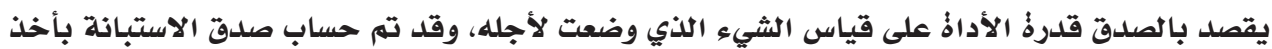
الجذر التربيعي لمعامل الثبات. 
ويمكن توضيح ذلك بالتفصيل ِِّ الجلدول (3) على النحو الآتي: جدول (3): ثبات وصدق الاستبانة

\begin{tabular}{|c|c|c|c|}
\hline الصدق & معامل(a) & المحور & الرقم \\
\hline 0.983 & 0.920 & الاحتياجات التدريبية التربوية & 1 \\
\hline 0.926 & 0.886 & الاحتياجات التدريبية الأكاديمية & 2 \\
\hline 0.954 & 0.903 & الاستبانة ككل & \\
\hline
\end{tabular}

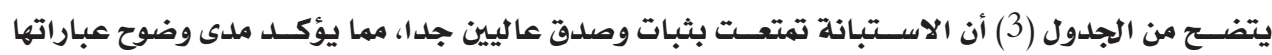
بالنسبة لأفراد العينة. المعالجات الإحصائية للبيانات :

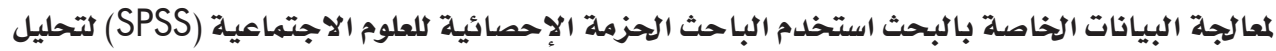

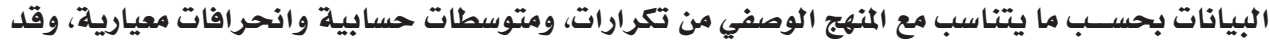

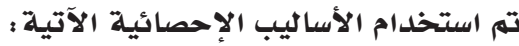

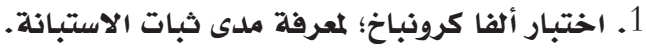

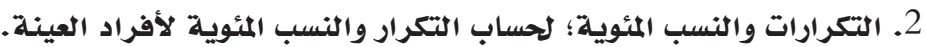

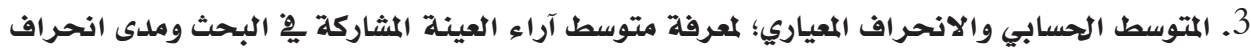
إجابات العينة عن متوسطها. المقياس المعتهد :

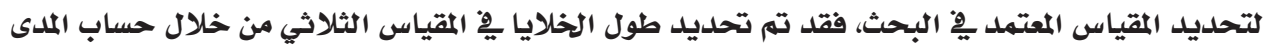

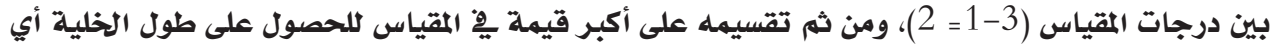

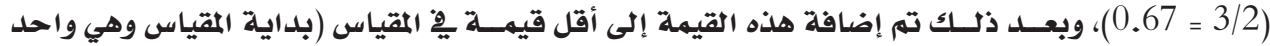

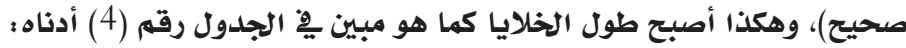
جدول (4) : المقياس المعتمد بِّ البحث

\begin{tabular}{|c|c|}
\hline درجة الموافقة & طول الخلية \\
\hline منخفضة & من 1 إلى 1.67 \\
\hline متوسطة & من 1.68 إلى 2.34 \\
\hline كبيرة & من 2.35 إلى 3.00 \\
\hline
\end{tabular}

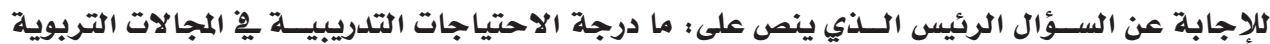

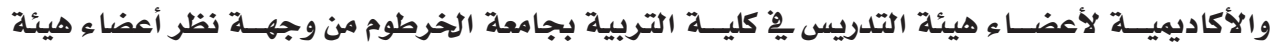

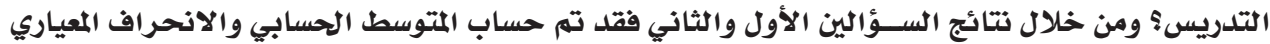

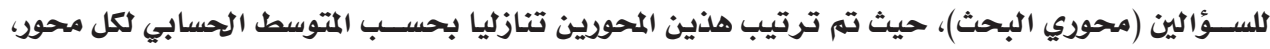

$$
\text { ويبين ذلك الجدول (5). }
$$

جدول (5) : المتوسطات الحسابية والانحرافات المعيارية لمحوري الاحتياجات التدريبية مرتبة تنازليا

\begin{tabular}{|c|c|c|c|c|c|}
\hline درجة الحاجة & ترتيب المحور & الانحراف المعياري & المتوسط الحسابي & المحور & رقم المحور \\
\hline كبيرة & 1 & .62 & 2.43 & الاحتياجات التدريبية التربوية & 1 \\
\hline متوسطة & 2 & .72 & 2.26 & الاحتياجات التدريبية الأكاديمية & 2 \\
\hline 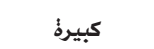 & -- & .67 & 2.35 & المجموع الكلي & \\
\hline
\end{tabular}




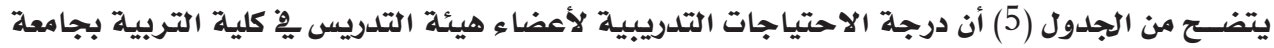

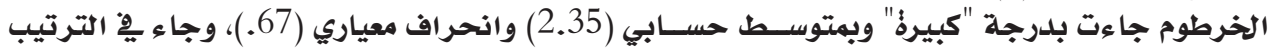

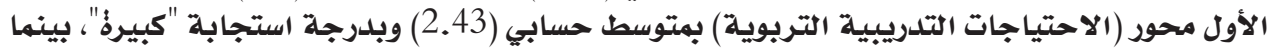

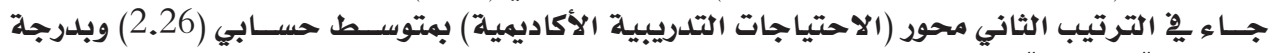
استجابة "متوسطة".

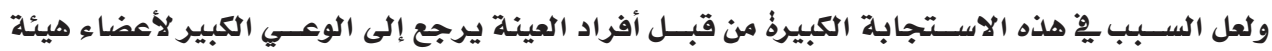

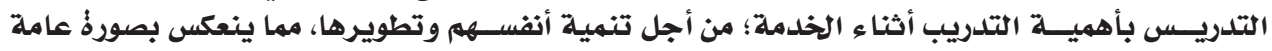

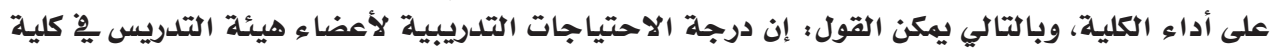
التربية بجامعة أداء الخرطوم وبالتياليكن "كبيرة".

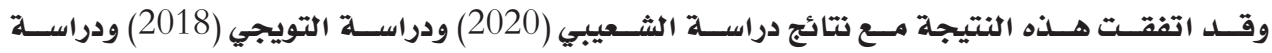

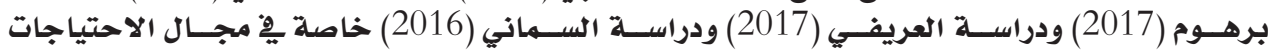

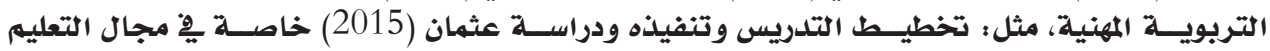

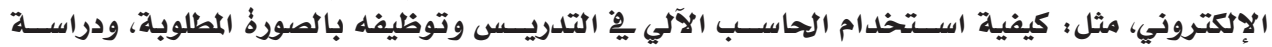

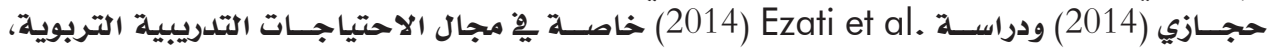

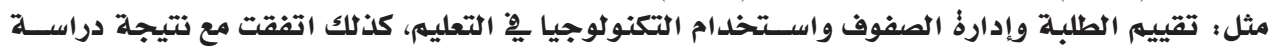

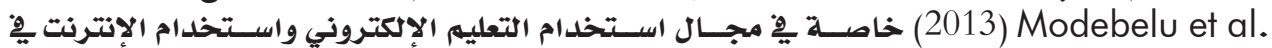

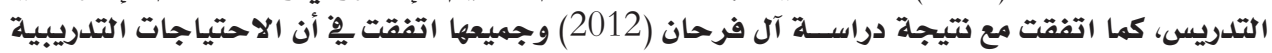
جاءت بلدرجة كبيرةُ. واختلفت مع نتائج دراسة الشريف (2019) ودراسة بدارنة وآخرين (2018) فقد توصلت تلك النتائج إلى أن الاحتياجات التدريبية جاءت دراءت بلدرجة متوسطة. ولمزيلد من التفصيل فقد تم رصد ومناقشة نتائج كل سؤال على حدةٌ، وذلك ِِِ الآتي: لإجابة عن السؤال الأول والذي نصه : ما درجة الاحتياجات التدريبية التربوية الأعضاء هيئة التدريس

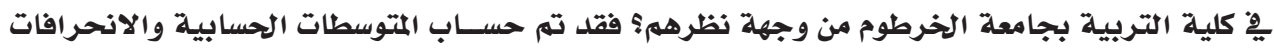

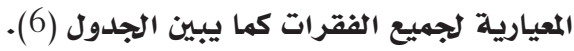

جلدول (6): المتوسطات الحسابية والانحرافات المعيارية للاحتياجات التدريبية التربوية مرتبة تنازليا

\begin{tabular}{|c|c|c|c|c|c|}
\hline الحاجة & الترتيب & الانحراف & المتوسطابي & الفقرات & رقم \\
\hline كبيرة & 1 & .51 & 2.77 & التعلم الإكتروني & 1 \\
\hline 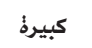 & 2 & .55 & 2.72 & التقنيات الحديثة واستخداماتها & 3 \\
\hline 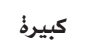 & 3 & .60 & 2.59 & التخطيط الاستراتيجي ٍِِ مجال التعليم & 4 \\
\hline 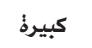 & 4 & .61 & 2.54 & الجودةٌ الشاملة ِِْ مجال التعليم & 6 \\
\hline 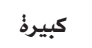 & 5 & .61 & 2.49 & القياس والتقويم التربوي & 9 \\
\hline 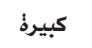 & 6 & .61 & 2.44 & الاتجاهات الحديثة يِّ الإدارةٌ التربوية & 5 \\
\hline 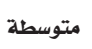 & 7 & .67 & 2.31 & المنهج ومكوناته & 2 \\
\hline 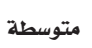 & 8 & .73 & 2.31 & مهارات البحث التربوي & 10 \\
\hline 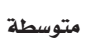 & 9 & .67 & 2.22 & الاتجاهات الحلديثة يِّ علم النفس التربوي & 8 \\
\hline 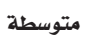 & 10 & .66 & 1.96 & تاريخ التربية والتعليم ِِّ السودان & 7 \\
\hline 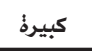 & -- & .62 & 2.43 & 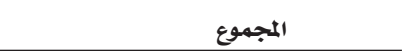 & \\
\hline
\end{tabular}




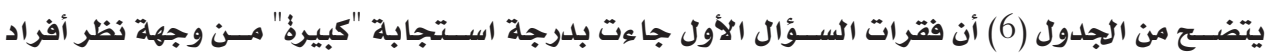

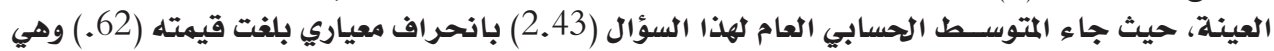

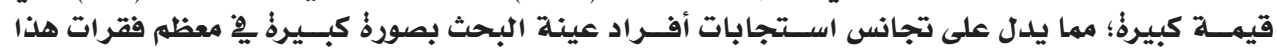
السؤال.

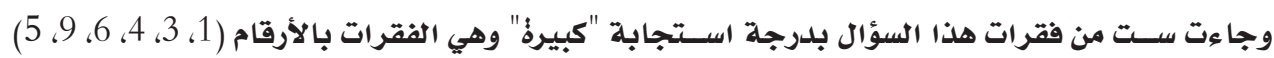

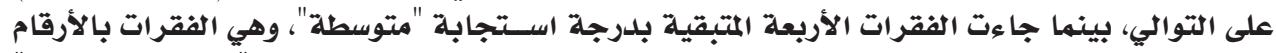

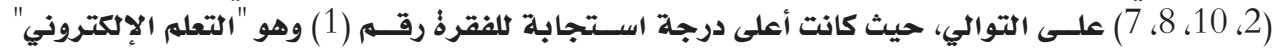

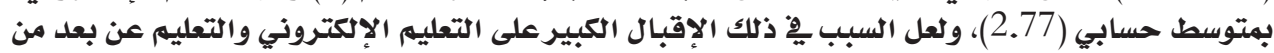

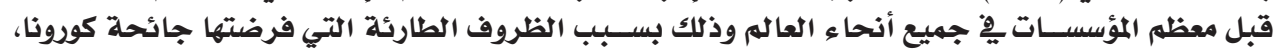

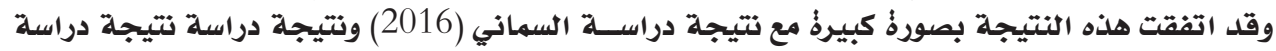
أدو ورجي Modebelu et al.

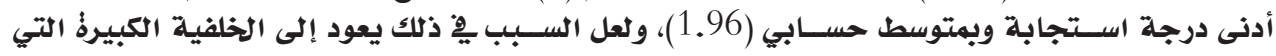

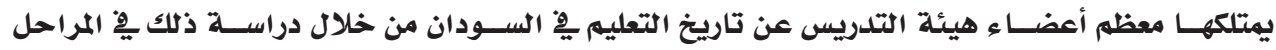
الدراسية المختلفة.

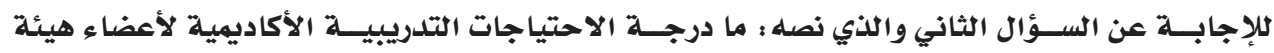

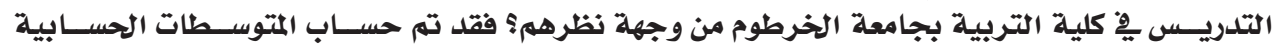

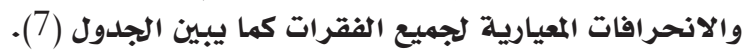

جدول (7) : المتوسطات الحسابية والانحرافات المعيارية للاحتياجات التدريبية الأكاديمية مرتبة تنازليا

\begin{tabular}{|c|c|c|c|c|c|}
\hline الحاجة & الترتيب & الانحراف المعياري & الحتوسطابي & الفقرات & رقهم \\
\hline كبيرة: ك كبر & 1 & .59 & 2.65 & برامج التحليل الإحصائي & 1 \\
\hline كبيرة & 2 & .69 & 2.58 & مهارات اللغة الإنجليزية & 5 \\
\hline كبيرة & 3 & .68 & 2.46 & مهارات الحاسب الآلي & 7 \\
\hline 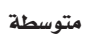 & 4 & .70 & 2.32 & مهارات اللغة العربية & 4 \\
\hline متوسطة & 5 & .72 & 2.24 & العلوم الطبيعية & 9 \\
\hline 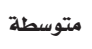 & 6 & .75 & 2.09 & الثقافة الغذائية & 8 \\
\hline 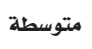 & 7 & .81 & 2.06 & تربية وتعليم أطفال ما قبل المدرسة & 6 \\
\hline 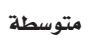 & 8 & .78 & 2.01 & جغرافية السودان والعالم & 2 \\
\hline 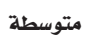 & 9 & .74 & 1.97 & تاريخ السودان القديم والحديث & 3 \\
\hline متوسطة & -- & .72 & 2.26 & المجموع & \\
\hline
\end{tabular}

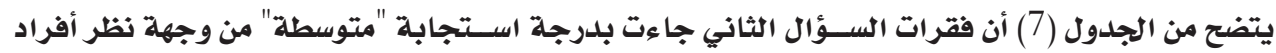

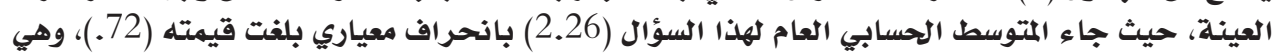

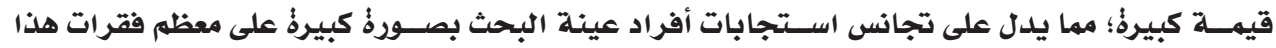
السؤاد.

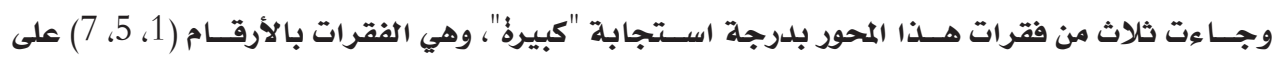

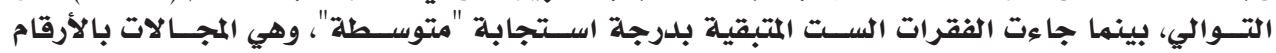

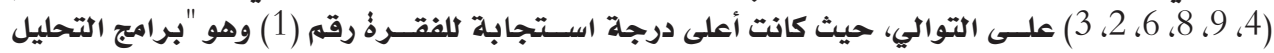

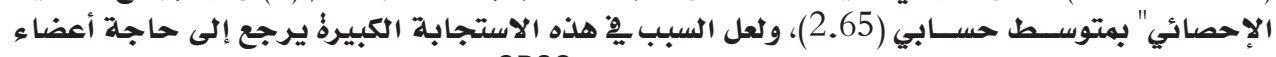

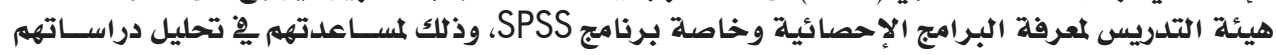

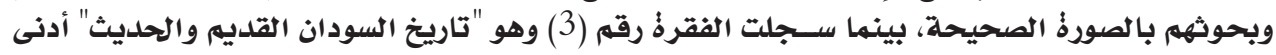


درجة اســتجابة وبمتوسط حسابي (1.97)، ولعل السـبب يفّ ذلك يعود إلى الخلفية الكبيرةٌ التي يمتلكها

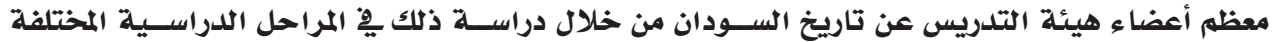

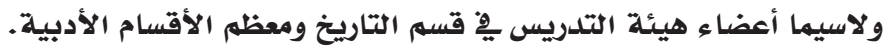

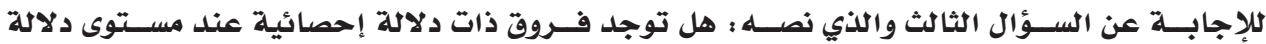

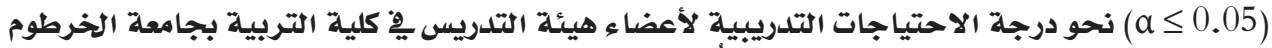

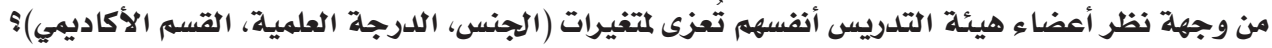

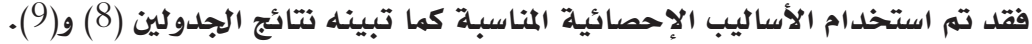

\begin{tabular}{|c|c|c|c|c|c|c|c|}
\hline الاستنتاج & مستوى المعنوية & درجة الحرية & قيمة ت & الانحراف المعياري & المتوسطابي & العدد & الجنس \\
\hline غير دالة، أي لا & 0886 & 95 & 0020 & 7.03 & 44.7 & 37 & ذكر \\
\hline توجد فروق & 0.000 & & 0.020 & 8.08 & 44.9 & 60 & أنثى \\
\hline
\end{tabular}

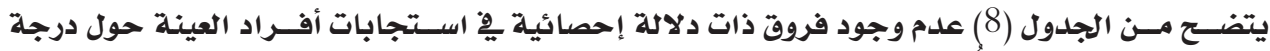

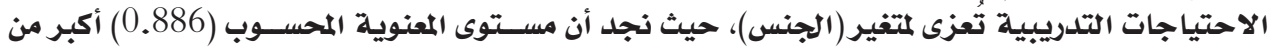

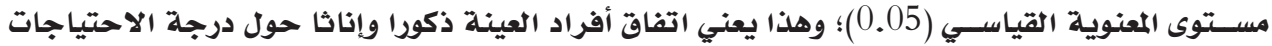

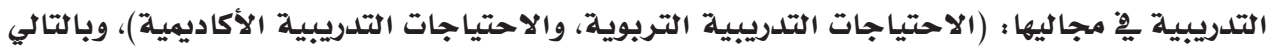

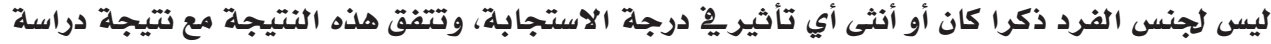

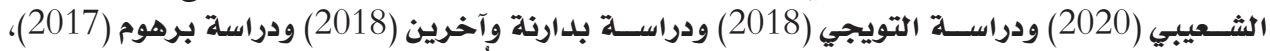
حيث أشارت نتائجها إلى علدم وجود فروق ذات دلالة إحصائية تعزى لمتفير الجنس.

\begin{tabular}{|c|c|c|c|c|c|c|}
\hline الاستنتاج & مستوى المعنوية & الفائية النسبة & الأوساط مربع & درجة الحرية & مجموع المربعات & المصدر \\
\hline دالة، أي توجد & 0.037 & 2.94 & 163.09 & 3 & 489.2 & بين المجموعات \\
\hline \multirow[t]{2}{*}{ فروق } & & & 55.4 & 93 & 5155.4 & داخل المجموعات \\
\hline & & & & 96 & 5644.6 & المجموع \\
\hline
\end{tabular}

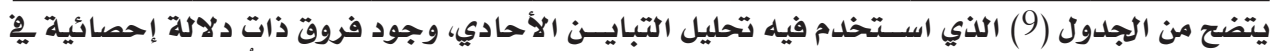

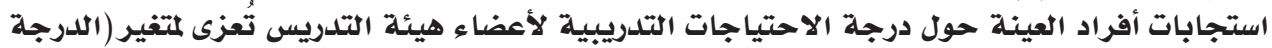

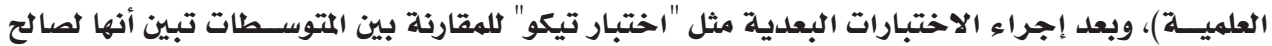

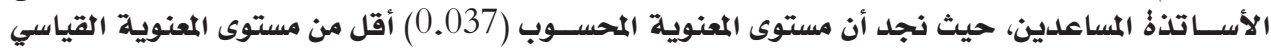

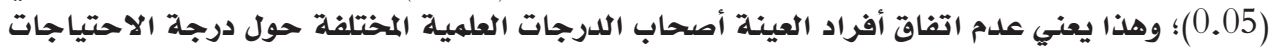

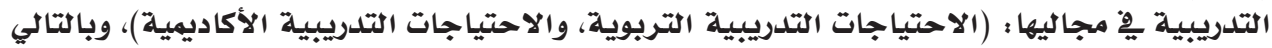

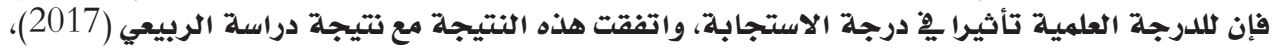

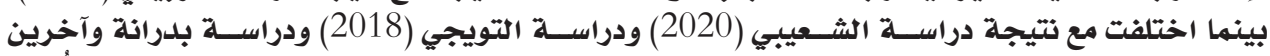

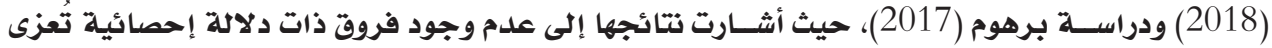

المتغير الدرجة العلمية.

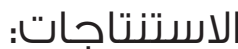

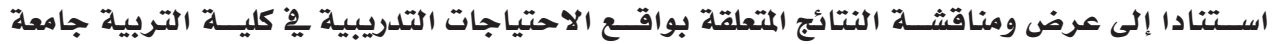

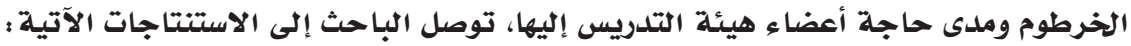

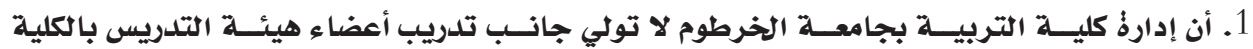

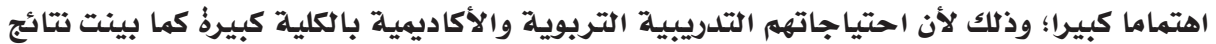


2. هناســك اهتمام كبير من أعضاء هيئة التدريس بأمر التدريـبـ من أجل تطوير معارفهم ومهاراتهم بِ

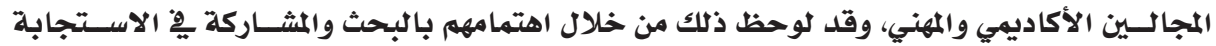

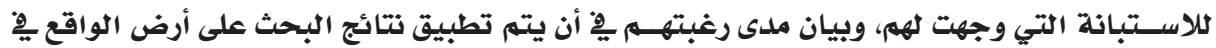

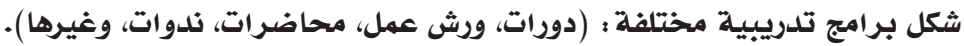

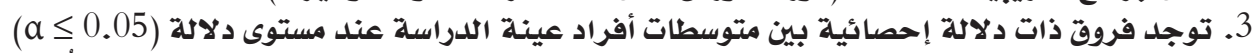

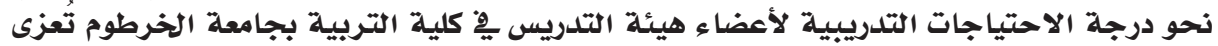

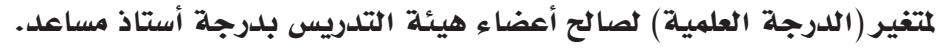

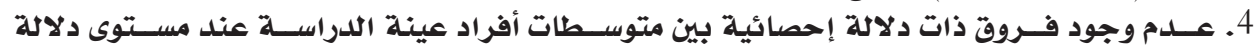

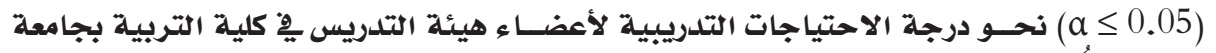
الخرطوم تُعزى لمتغير (الجنس). التوصيات:

من خلال الاستنتاجات التي تم التوصل إليها يوصي الباحث بالآتي:

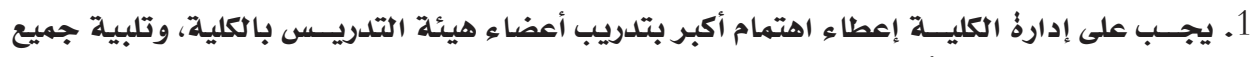

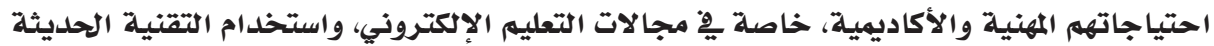

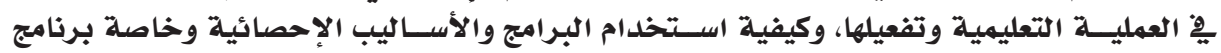
.SPSS

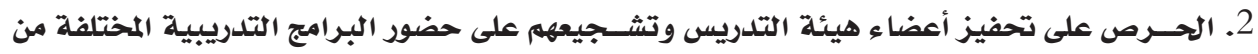

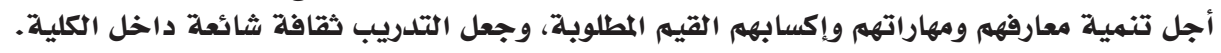

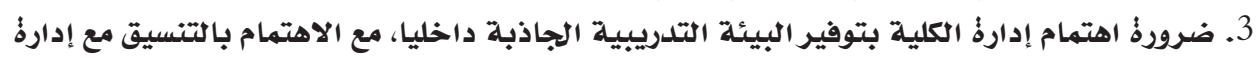

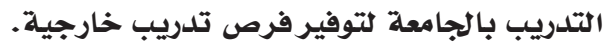
المغترحات: يقترح الباحث إجراء الدراسات والأبحاث الآتية :

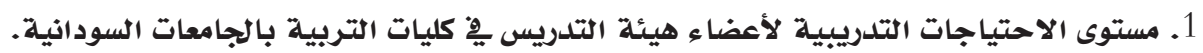

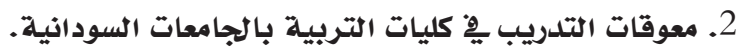

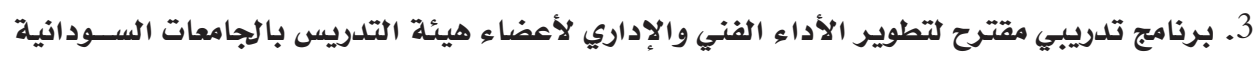

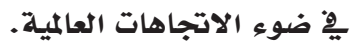
المراجع: الأحمــد، خالد طه (2005). تكوين المعلهين من الإعلداد إلى التلدريـب (ط11)، الإمارات العربية المتحدة: : دار الكتاب الجامعي.

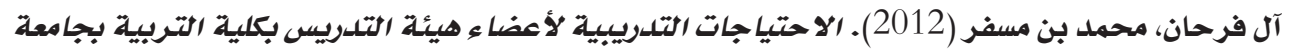

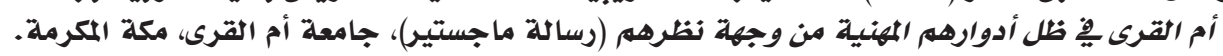

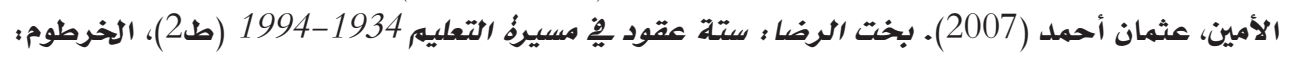

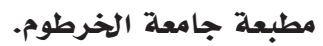

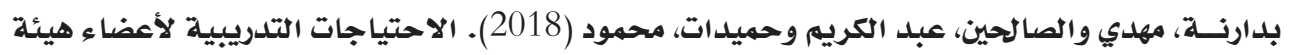

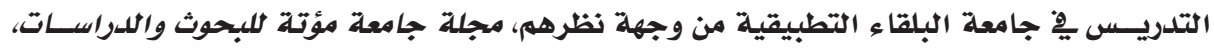
.120-93، (3) (3) (2017)

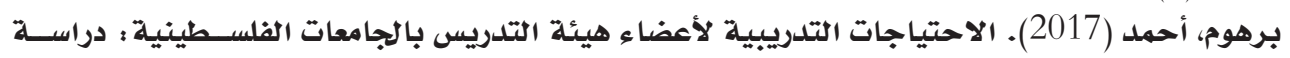

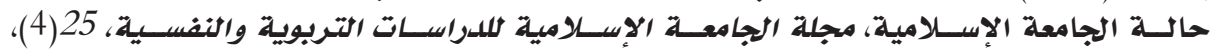
.369-347 جوذة التعليم الجامعي 


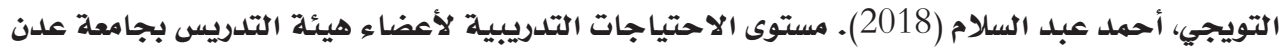

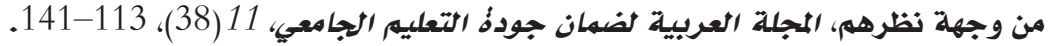

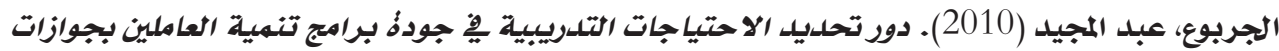

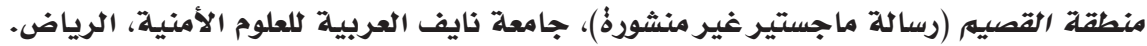

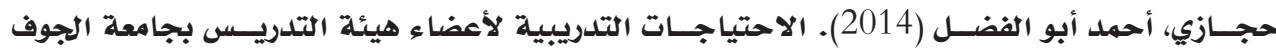

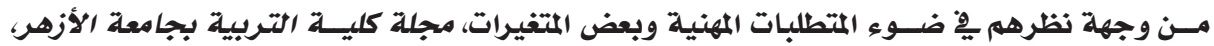
907-867، 161) 1

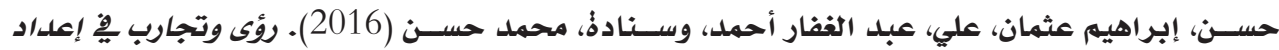

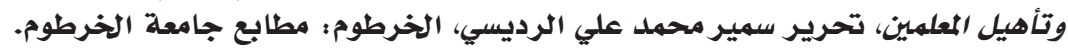

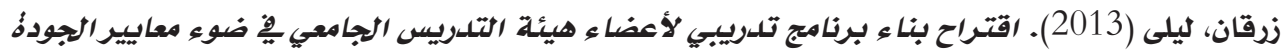

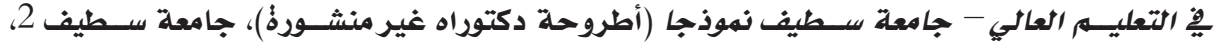
الجزائر. السالم، مؤيد سعيد (2009). إدارةٌ الموارد البشريية : ملدخل استراتيجي تكاملي (ط1)، عمان : إثراء للنشر والتوزيع.

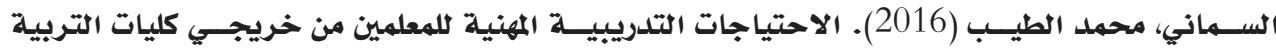

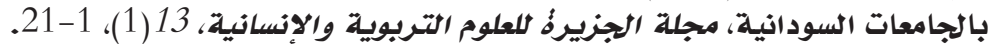

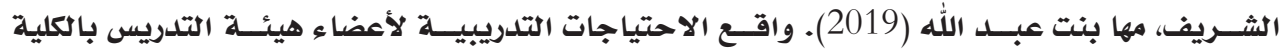

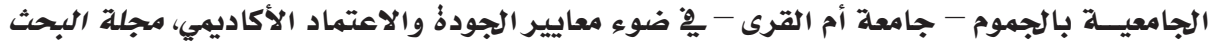

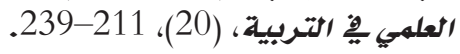

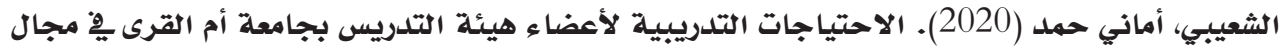

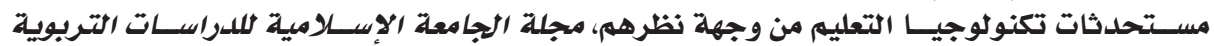

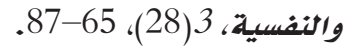
طعيمة، رشــدي أحمد، والبندري، محمد سليمان (2004)، التعليم الجامعي بين رصلد الواقع ورؤى التطوير

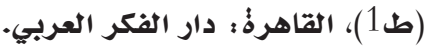

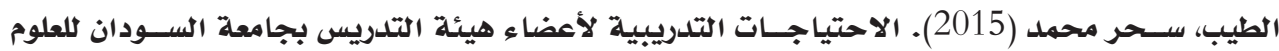

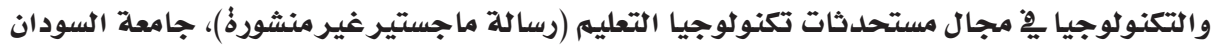
للعلوم والتكنولوجيا، السودان.

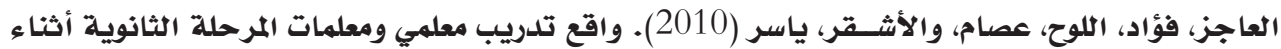

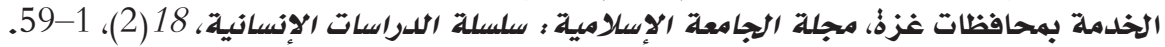

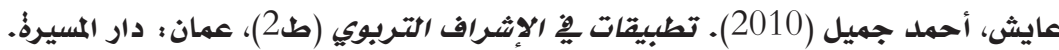

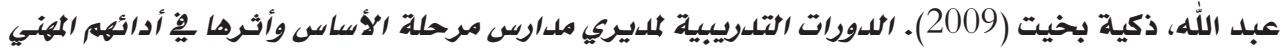

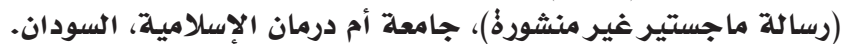

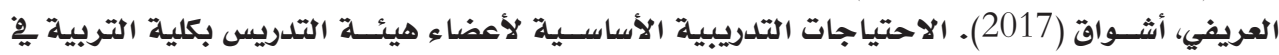

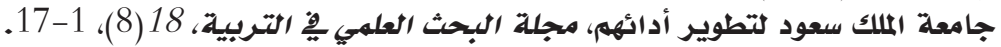

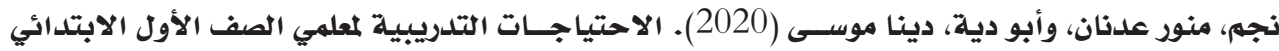

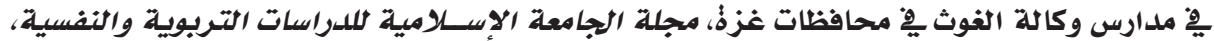
.80-48، 1 
Ezati, B. A., Opolot-Okurut, C., \& Ssentamu, P. N. (2014). Addressing pedagogical training needs of teaching staff: lessons from Makerere University short professional development programs 2006-2010. American Journal of Educational Research, 2(12), 1190-1198.

Modebelu, M., Adanama, D., Nnennaya, K., \& Ada, I. (2013). Knowledge and learning management for enhancing academic staff online training methodologies for quality graduates. The International Conference on E-Learning in the Workplace, 12-14 June, New York.

\section{Arabic References:}

Abduallah, Dhakiat Bakhit (2009). Aldawrat altadribiat limudiri madaris marhalat alasas wathariha fi adaihim almehani (Resalat majstyr), Jamieat Om Darman Aleslamiat, Al-Sudan.

Aesh, Ahmad Jamil (2010). Tatbaeqat fi aleshraf altrbawi (†2), Amman: Dar Almasirat.

Al farhan, Muhamad Bin Masafr (2012). Alaihtiajat altadribiat liaada'a hayyat altadris bikoliat altarbiat bijamieat Om Alquraa fi zil adwarihim almihniat min wijhat nazarhom (Resalat majstyr), Jamieat Om Alquraa, Makat Almukramat.

Alahmad, Khalid Taha (2005). Takwin almualimin min alaeadad ela altadrib (†1), Alemarat Flarabiat Almutahedt: Dar Alkitab Aljamiei.

Alajiz, Fuad, Allawh, Esam, Walashqar, Yasir (2010). Waqia tadrib moalemin wamualimat almarhalat althanawiat athna'a alkhidmat bimuhafazat Ghazah, Majalat Aljamieat Aleslamiat: Silsilat Aldirasat Alensaniat, 18(2), 1-59.

Alamin, Uthman Ahmad (2007). Bakht alredha: setat uqud fi masirat altalim 1934-1994 (†2), Alkhartum: Mutbaat Jamieat Alkhartum.

Alarifi, Ashwaq (2017). Alaihtiajat altadribiat alasasiat liaada'a hayyat altadris bikoliat altarbiat fi Jamieat Almalik Seud litatwir adaihim, Majalat Albahth Alelmi fi Altarbiati, 18(8), 1-17.

Aljurbue, Abdulmaiid (2010). Dawr tahdid alaihtiajat altadribiat fi jawdat baramij tanmiat aleamilin bijawazat mintaqat alqsym (Rsalat majstayr), Jamieat Nayif Alearabiat Lileulum Al'amniati, Al-Riyadh.

Alsalim, Muaid Saeed (2009). Edarat almawarid albashariah: Madkhal estratiji takamuli (†1), Amman: Ethra'a Lilnashr Waltawzia.

Alsamani, Muhamad Altayib (2016). Alaihtiajat altadribiat almihniat lilmualimin min kheriji kulyat altarbiat bialjamieat alsuwdaniat, Majalat Aljazirat Lilelum Altarbawiat Walensaniat, 13(1), 1-21. 
Alsharif, Maha Bent Abduallah (2019). Waqia alaihtiajat altadribiat liaada'a hayyat altadris bialkuliat aljamiaiah bialjamum - Jamieat Om Alquraa fi daw'a maeir aljawdat walaetimad alakadimi, Majalat Albahth Alelmi fi Altarbiati, (20), $211-239$.

Alshoaebi, Amani Hamd (2020). Alaihtiajat altadribiat liaada'a hayyat altadris bijamieat Om Alquraa fi majal mustahdathat tiknulujia altaelim min wijhat nazarhom, Majalat Aljamieat Aleslamiat Lildirasat Altarbawiat Walnafsiat, 3(28), 65-87.

Altiyb, Sahr Muhamad (2015). Alaihtiajat altadribiat liaada'a hayyat altadris bijamieat Alsuwdan lilulum waltiknulujia fi majal mustahdithat tiknulujia altalim (Resalat majstyr), Jamieat Alsuwdan Lilulum Waltiknulujia, Al-Sudan.

Altwaeji, Ahmad Abdualsalam (2018). Mustawa alaihtiajat altadribiat liaada'a hayyat altadris bijamieat Aden min wijhat nazarhom, Almajalat Alarabiat Lidhaman Jawdat Altalim Aljamiei, 1 1(38), $113-141$.

Badranah, Mahdi Walsalihin, Abdualkarim wa Hamidat, Mahmud (2018). Alaihtiajat altadribiat liaada'a hayyat altadris fi jamieat Albalqa'a altatbiqiat min wijhat nazarhom, Majalat Jamieat Muatah Lilbohooth Waldirasat, 3(3), 93-120.

Barhoom, Ahmad (2017 Alaihtiajat altadribiat liaada'a hayyat altadris bialjamieat alfilsteneah: Dirasat halat aljamieat aleslamiat, Majalat Aljamieat Aleslamiat Lildirasat Altarbawiat Walnafsiat, 25(4), 347-369.

Hasan, Ibrahim Uthman, Ali, Abdualghafaar Ahmad, wa Sanadat, Muhamad Hasan (2016). Rua'a Watajarob fi eadad watahil almualimin, Tahrir Samir Muhamad Ali Alrodaesy, Alkhartuma: Matabia Jamieat Alkhartum.

Hijazi, Ahmad Abu Alfadhl (2014). Alaihtiajat altadribiat liaada'a hayyat altadris bijamieat Aljawf min wijhat nazarhom fi dawa almutatalabat almihniat wabaad almutaghayirat, Majalat Kuliyat Altarbiat Bijamieat Alazhar, 1(161), 867-907.

Najm, Munwr Adnan, Wa Abu Diat, Dina Musa (2020). Alaihtiajat altadribiat limualimi alsaf alawal alaibtidai fi madaris wikalat Alghawth fi muhafazat Ghazah, Majalat Aljamieat Aleslamiat Lildirasat Altarbawiat Walnafsiat, $7(28)$, 48-80.

Toaimat, Roshdi Ahmad, W Albandari, Muhamad Suleman (2004). Altaelim aljamiei baen rasd alwaqia waroa'a altatwir (†1), Alqaherh: Dar Alfikr Alarabi.

Zorqan, Layla (2013). Eqtirah bina'a barnamaj tadribi liaada'a hayyat altadris Aljamiei fi daw'a maeyir aljawdat fi altalim alali - Jamieat Satif nomodhajan (Utrwhat Dukturah), Jamieat Satif 2, Al-Jazair. 